\title{
Just when you thought you'd seen everything
}

\author{
Siva Raja, MD, PhD, and Sudish C. Murthy, MD, PhD
}

\footnotetext{
From the Department of Thoracic and Cardiovascular Surgery, Heart and Vascular Institute, Cleveland Clinic, Cleveland, Ohio.

Disclosures: Authors have nothing to disclose with regard to commercial support.

Received for publication Aug 15, 2016; accepted for publication Aug 19, 2016; available ahead of print Sept 28, 2016.

Address for reprints: Siva Raja, MD, PhD, Department of Thoracic and Cardiovascular Surgery, Cleveland Clinic, 9500 Euclid Ave, Desk J4-1, Cleveland, OH 44195 (E-mail: rajas@ccf.org).

J Thorac Cardiovasc Surg 2016;152:e133

$0022-5223 / \$ 36.00$

Copyright (C) 2016 Published by Elsevier Inc. on behalf of The American Association for Thoracic Surgery http://dx.doi.org/10.1016/j.jtcvs.2016.08.028
}

We read with some interest the report submitted by Ditah and colleagues ${ }^{1}$ in this issue of the Journal, which reviews a case of hemoptysis in a 19-year-old woman. The story sounded familiar, and even after skimming over the title, the answer seemed to be as well rehearsed as the latest production of Phantom of the Opera (now 30 years into its iconic run). Hemoptysis in a 19-year-old? Carcinoid, mucoepidermoid tumor, broncholith, lymphoma, foreign body, arteriovenous malformation, sequestration, trauma, pulmonary embolism, sarcoma, adenoma, trauma, andreaching way out into left field-even Eisenmenger syndrome or perhaps Castleman disease are the usual suspects. Then, of course, there is always the misdirection play in which epistaxis is the actual root cause.

As we continued reading, however, all of our certainty dissipated. The comprehensive differential diagnosis of hemoptysis, of which we were so proud and that seemed so exhaustive to us, unfortunately did not include intrapulmonary teratoma. Ditah and colleagues ${ }^{1}$ had identified a vascularized right middle lobe tumor. Embolization was initially performed, and then on subsequent resection a mature teratoma was found.

Intrapulmonary teratomas have been described before, but one being heralded by hemoptysis is novel and enlightening. Trichoptysis (expectoration of hair) is the usual Final Jeopardy answer and is pathognomonic for teratoma. Hemoptysis is rarely mentioned in the existing literature.

There are a few other noteworthy points. It has been our institutional practice to perform tumor embolization for systemically vascularized thoracic lesions before resection to decrease intraoperative blood loss and facilitate a safer resection. Some argue about the utility of such a practice, but we have seldom regretted being too well prepared for an operation.

We might differ from Ditah and colleagues, ${ }^{1}$ however, on one operative point. The authors initially describe a videoassisted thoracoscopic surgery approach, followed by conversion to eventual thoracotomy. We perhaps might have gone straight to the thoracotomy in this case, although insight.

\section{Reference}

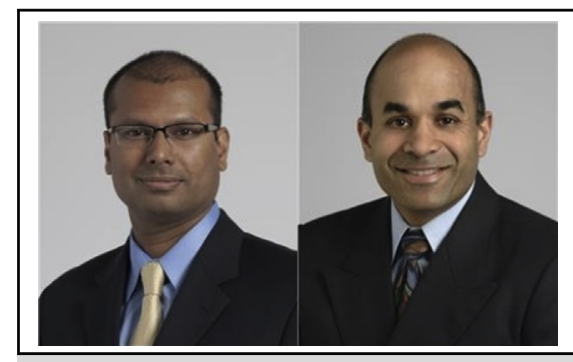

Siva Raja, MD, PhD (left), and Sudish C. Murthy, MD, $\mathrm{PhD}$ (right)

Central Message

This report on the case of an intrapulmonary teratoma describes an uncommon presentation (hemoptysis) of a rare tumor. It highlights the management of systemically vascularized intrapulmonary lesions.

See Article page e129.

we did appreciate the less invasive attempt. Our experience suggests it is seldom how you get there that is a problem (especially in a 19-year-old), but rather what you do when you are there! Also in our experience, we have used a video-assisted thoracoscopic surgery exploration in these cases to rule out pleural metastasis and generally survey the hemithorax, but have used an open approach for safety reasons. Embolization is often only partially effective, and, paradoxically, an open procedure and easy sponge stick access is more comforting to us for these difficult cases.

In this era of large, randomized, controlled trials, studies of rare diseases and lesions are frequently relegated to scattered case reports and small case series in throwaway journals often not in the English language. Over time, however, even if on the order of decades, these curious, yet spurious, reports eventually amount to an accumulated experience that translates into important information and valuable

Common presenting symptoms in the setting of a common clinical picture should not distract the clinician from entertaining rare clinical entities. Those who think that they know it all don't know enough, and those who recognize that they don't know enough never stop learning.

1. Ditah C, Templin T, Mandal R, Pinchot JW, Macke RA. Isolated intrapulmonary teratoma. J Thorac Cardiovasc Surg. 2016;152:e129-31. 